\title{
Pollen morphology and character evolution in the subtribe Neoguillauminiinae (Euphorbiaceae)
}

\author{
Ki-Ryong PARK* \\ Department of Environmental and Energy Engineering, Kyungnam University, Changwon 51767, Korea
}

(Received 17 December 2018; Revised 23 March 2019; Accepted 21 June 2019)

\begin{abstract}
A pollen morphological study was conducted using light and scanning electron microscopy involving six species belonging to the subtribe Neoguillauminiinae. Pollen samples from the six species are tricolporate, and the colpi are surrounded by broad margo, with the widest width in the equator, narrower toward the pole, and rounded at the end. Based on the pollen morphology, pollen of the species in the subtribe Neoguillauminiinae were divided into four types: the Neoguillauminia type (T1), the C. collinus type (T2), the C. casuarinoides type (T3) and the C. paucifolius type (T4). The generic divergence between Neoguillauminia and Calycopeplus was supported by the pollen characters of the size, amb and lumina shape. In particular, the traits of rounded shape in the outline of the polar view and circular lumina, which appear only in the pollen grains of N. cleopatra, support the recognition of Neoguillauminia as a monotypic genus. Calycopeplus oligandrus and C. paucifolius had the same reticulate pattern of pollen grains, supporting Forster's hypothesis that these two species are closely related. On the other hand, the close relationship between the morphologically similar C. collinus and C. casuarinoides was not supported by the pollen characters. Within the subtribe there are two equally parsimonious hypotheses regarding the evolution of exine characters. The first consists of two changes of microreticulate through parallel evolution from the primitive reticulate exine, and the second is that the microreticulate pattern is differentiated from the reticulate state and then reversed to reticulate pollen grains.
\end{abstract}

Keywords: pollen morphology, Neoguillauminia, Calycopeplus, Neoguillauminiinae, Euphorbiaceae

Subtribe Neoguillauminiinae Croizat of the tribe Euphorbieae Blume was described by Croizat (1937) on the basis of genus Neoguillauminia Croizat which is a monotypic New Caledonian genus. Webster (1975) then included Calycopeplus Planchon, an endemic genus of Australia, in subtribe Neoguillauminiinae, based on the shared feature such as pseudopetals being developed from involucral bracts. Unlike Neoguillauminia, Calycopeplus, an Australian endemic genus, has four cyathial glands, small involucral bracts and opposite leaves, and recently five species have been reported by Forster (1995). According to the most recent classification system, the tribe Euphorbieae is divided into three subtribes, Anthosteminae (Baillon) Webster, Neoguillauminiinae and Euphorbiinae Hurusawa, and six species, N. cleopatra (Baill.) Croizat, $C$. casuarinoides L. S. Sm., C. collinus P. I. Forster, C. marginatus Benth., C. oligandrus P. I. Forster, and $C$. paucifolius (Klotzsch) Baill., placed into subtribe Neoguillauminiinae (Webster, 1994; Forster, 1995).

Recent phylogenetic analysis based on morphological and molecular data strongly support monophyly of subtribe Neoguillauminiinae and the sister-group relationship between Neoguillauminia and Calycopeplus (Park and Backlund, 2002; Steinmann and Porter, 2002). Although Neoguillauminia and Calycopeplus belong to the same subtribe, traditionally Calycopeplus has been regarded as closely related to Euphorbia (Forster, 1995) or has been considered as direct ancestor of Euphorbia of the subtribe Euphorbiinae (Croizat, 1937).

Except for a limited pollen study in subtribe Neoguillauminiinae (Park and Lee, 2013; Suárez-Cervera et al., 2001), a thorough investigation of pollen morphology and systematic relationship based on pollen characters has not been undertaken. Previous study showed that the pollen grains of subtribe

\footnotetext{
*Author for correspondence: park@kyungnam.ac.kr
} 
Neoguillauminiinae were subprolate and microreticulate in $N$. cleopatra, and the foot layer was thick and continuous in $C$. paucifolius (Park and Lee, 2013). Suárez-Cervera et al. (2001) suggested that the presence of the big granulae in the inner part of fissured endexine should be a synapomorphic character among species in subtribe Neoguillauminiinae.

The aim of this study is to describe the types of pollen morphology among all the species in subtribe Neoguillauminiinae, and propose a pollen character evolution within the subtribe.

\section{Materials and Methods}

Pollen grains of all six species in the subtribe Neoguillauminiinae were obtained from the herbarium specimens and their information were cited according to the recent code (Thiers, 2018) (Table 1). Pollen grains were acetolysed using the methods presented by Erdtman (1960). The polar length, equatorial diameter and colpus length were measured from more than 10 pollen grains per species under the light microscopy (LM), and the mean value and its ranges were used (Table 1). To observe by scanning electron microscopy (SEM), acetolysed pollen grains were coated with $\mathrm{Au}-\mathrm{Pd}$ for 1 min under 0.1 Torr by ion-sputter. Pollen grains were examined with FE-SEM, Hitachi S-4200. SEM photographs were used to observe the exine scrupturing pattern, and the widths of lumina and muri were measured for each of 10 samples, and their average values were calculated (Figs. 1, 2, Table 1). The terminology for the pollen characters follows Punt et al. (2007).

In order to propose an evolutionary hypothesis of pollen character, a parsimonious interpretation was made by applying pollen characters to the simplified phylogenetic relationships proposed by Steinmann and Porter (2002).

\section{Results}

Pollen grains of subtribe Neoguillauminiinae have polar length that ranges from 27.5 to $58.7 \mu \mathrm{m}$, equatorial diameters that range from 31.3 to $45.0 \mathrm{um}$, and are suboblate to subprolate $(\mathrm{P} / \mathrm{E}=0.85-1.28)$. Amb shapes of the subtribe were semiinterangular or circular. All six species of subtribe Neoguillauminiinae are tricolporate, and the colpi were surrounded by a broad margo, with the widest width in the equator, narrower toward the pole, and rounded at the end (Figs. 1, 2).

Three exine scrupturing patterns are present. Three of six species in this subtribe are microreticulate while the remaining three species have reticulate or perforate pollen grains (Figs. 1, 2, Table 1). Monotypic Neoguillauminia has a microreticulate pollen grains with small and sparsely distributed supratectal elements (Fig. 2F).

Two equally parsimonious reconstructions (Fig. 3A, B) were obtained by placing exine character states in a recent molecular phylogenetic tree (Steinmann and Porter, 2002) to investigate the change of pollen character states in subtribe Neoguillauminiinae.

Based on the pollen characters observed using LM, SEM and previous transmission electron microscope studies (Park and Lee, 2013), six species belonging to subtribe Neoguillauminiinae were distinguished into four pollen types.

\section{Descriptions of pollen types}

1. T1: Neoguillauminia Type

Pollen grains 3-colporate, subprorate. $\mathrm{P}=45.0-58.7 \mu \mathrm{m}$, $\mathrm{E}=35.0-45.0 \mu \mathrm{m}$. Amb shape circular. Colpi 35.0-43.8 $\mu \mathrm{m}$ long with rounded ends, margins of colpi smooth, thick

Table 1. Pollen morphological data (minimum [mean] maximum) and voucher information of species in the subtribe Neoguillauminiinae.

\begin{tabular}{|c|c|c|c|c|c|c|c|}
\hline Taxon & $\begin{array}{l}\text { Polar } \\
\text { length }\end{array}$ & $\begin{array}{l}\text { Equatorial } \\
\text { diameter }\end{array}$ & $\begin{array}{l}\mathrm{P} / \mathrm{E} \\
\text { ratio }\end{array}$ & $\begin{array}{l}\text { Colpus } \\
\text { length }\end{array}$ & $\begin{array}{c}\text { Exine } \\
\text { structure }\end{array}$ & $\begin{array}{l}\text { Lumina } \\
\text { diameter }\end{array}$ & $\begin{array}{l}\text { Pollen } \\
\text { source }\end{array}$ \\
\hline N. cleopatra (Baill.) Croizat & $45.0(50.7) 58.7$ & $35.0(39.6) 45.0$ & 1.28 & $35.0(39.5) 43.8$ & $\begin{array}{l}\text { Micro- } \\
\text { reticulate }\end{array}$ & 0.81 & H. S. McKee 18870 (CANB) \\
\hline C. casuarinoides L. S. Sm. & $27.5(30.0) 32.5$ & $32.5(33.9) 35.0$ & 0.88 & $20.0(23.4) 25.0$ & Perforate & 0.32 & $\begin{array}{c}\text { A. V. Slee \& L. A. Craven } 2515 \\
\text { (BRI) }\end{array}$ \\
\hline C. collinus P. I. Forster & $37.5(38.5) 40.0$ & $31.3(32.0) 32.5$ & 1.20 & $30.0(31.3) 32.5$ & $\begin{array}{l}\text { Micro- } \\
\text { reticulate }\end{array}$ & 0.62 & L. A. Craven 5846 (BRI) \\
\hline C. marginatus Benth. & 27.5 (29.3) 31.3 & 32.5 (34.3) 36.3 & 0.85 & $20.0(21.5) 22.5$ & $\begin{array}{l}\text { Micro- } \\
\text { reticulate }\end{array}$ & 0.64 & C. A. Gardner 9219 (BRI) \\
\hline C. oligandrus P. I. Forster & $35.0(38.0) 40.0$ & $30.0(33.3) 35.0$ & 1.14 & $22.5(25.1) 28.8$ & Reticulate & 2.16 & A. R. Bean 9089 (BRI) \\
\hline C. paucifolius (Klotzsch) Baill. & $40.6(44.5) 50.0$ & 32.5 (34.9) 40.0 & 1.28 & $30.0(32.9) 37.5$ & Reticulate & 1.33 & L. A. Craven 7139 (BRI) \\
\hline
\end{tabular}


at the equator, tapered toward the poles. Exine sculpture microreticulate, lumina circular, $0.81 \mu \mathrm{m}$ in diameter. The muri $0.66 \mu \mathrm{m}$ wide with small supratectal elements.

Species included: Neoguillauminia cleopatra (Fig. 2E, F, Table 1).

\section{T2: C. collinus Type}

Pollen grains 3-colporate, subprorate to suboblate. $\mathrm{P}=27.5-$
$40.0 \mu \mathrm{m}, \mathrm{E}=31.3-36.3 \mu \mathrm{m}$. Amb shape semi-interangular. Colpi 20.0-32.5 $\mu \mathrm{m}$ long with rounded ends, margins of colpi smooth, thick at the equator, tapered toward the poles. Exine sculpture microreticulate, lumina shape irregular or round, $0.62-0.64 \mu \mathrm{m}$ in diameter. The muri $0.59-0.61 \mu \mathrm{m}$ mostly lacking supratectal elements.

Species included: Calycopeplus collinus (Fig. 1A, B, Table 1), C. marginatus (Fig. 1C, D, Table 1).
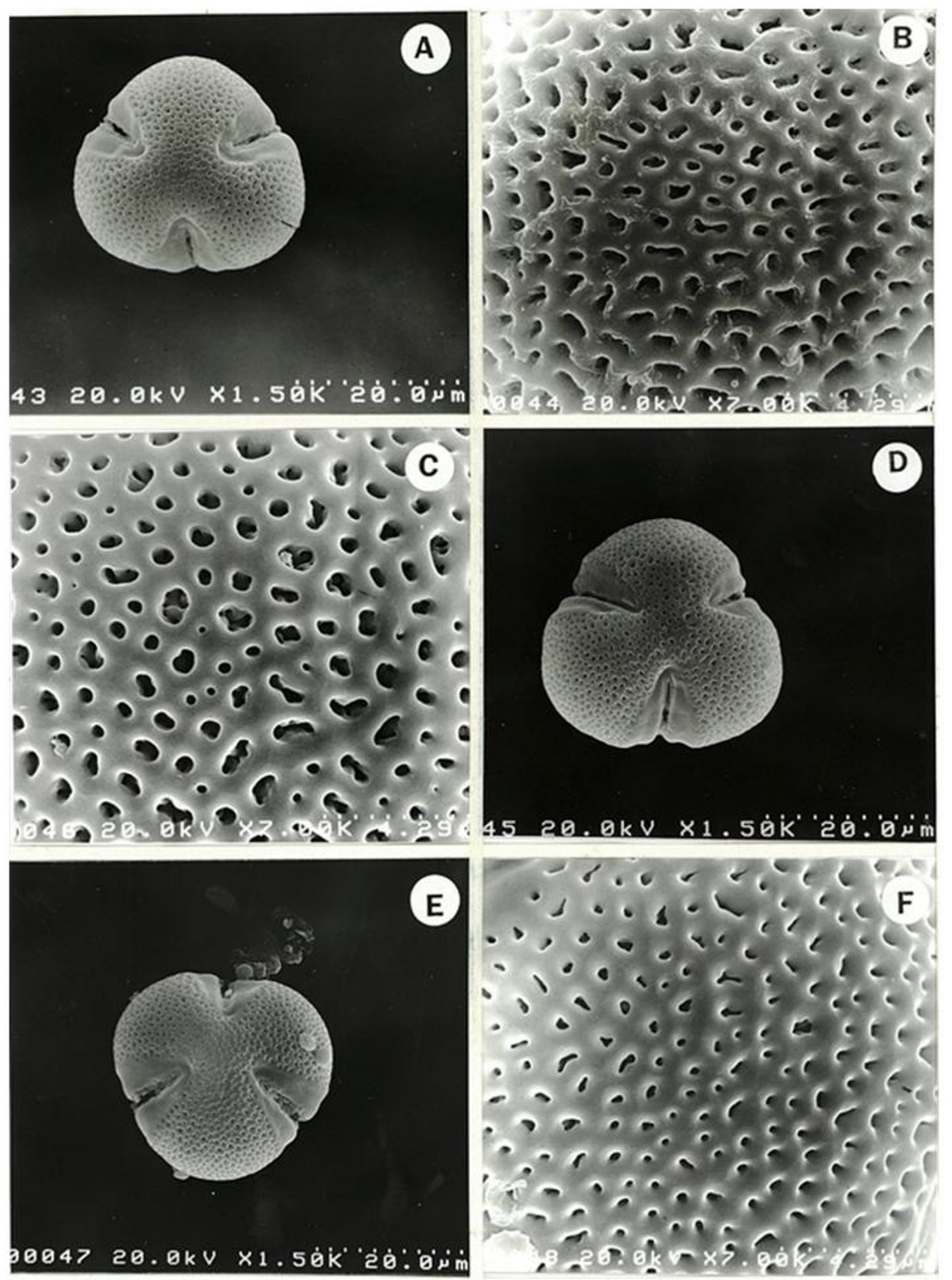

Fig. 1. Scanning electron microscopy micrographs of the subtribe Neoguillauminiinae species pollen. A, B. Calycopeplus collinus. C, D. C. marginatus. E, F. C. casuarinoides. B, C, F. Detail of the surface. 
3. T3: C. casuarinoides Type

Pollen grains 3-colporate, oblate-spheroidal. $\mathrm{P}=27.5$ $32.5 \mu \mathrm{m}, \mathrm{E}=32.5-35.0 \mu \mathrm{m}$. Amb shae semi-interangular. Colpi 20.0-25.0 $\mu \mathrm{m}$ long with rounded ends, margins of colpi smooth, thick at the equator, tapered toward the poles. Exine tectateperforate, perforations circular or irregular in case of fused of 2 to $3,0.32 \mu \mathrm{m}$ in diameter. The width of muri $0.77 \mu \mathrm{m}$.

Species included: Calycopeplus casuarinoides (Fig. 1E, F, Table 1).

\section{T4: C. paucifolius Type}

Pollen grains 3-colporate, subprorate to prolate-spheroidal. $\mathrm{P}=$ $35.0-50.0 \mu \mathrm{m}, \mathrm{E}=30.0-40.0 \mu \mathrm{m}$. Amb shape semi-interangular. Colpi $22.5-37.5 \mu \mathrm{m}$ long with rounded ends, margins of colpi smooth, sunken, thick at the equator, tapered toward the poles. Exine structure reticulate, lumina shape irregular, 1.33-2.16 $\mu \mathrm{m}$ in diameter. The muri $0.39-0.58 \mu \mathrm{m}$ wide.

Species included: Calycopeplus oligandrus (Fig. 2A, B, Table 1), C. paucifolius (Fig. 2C, D, Table 1).
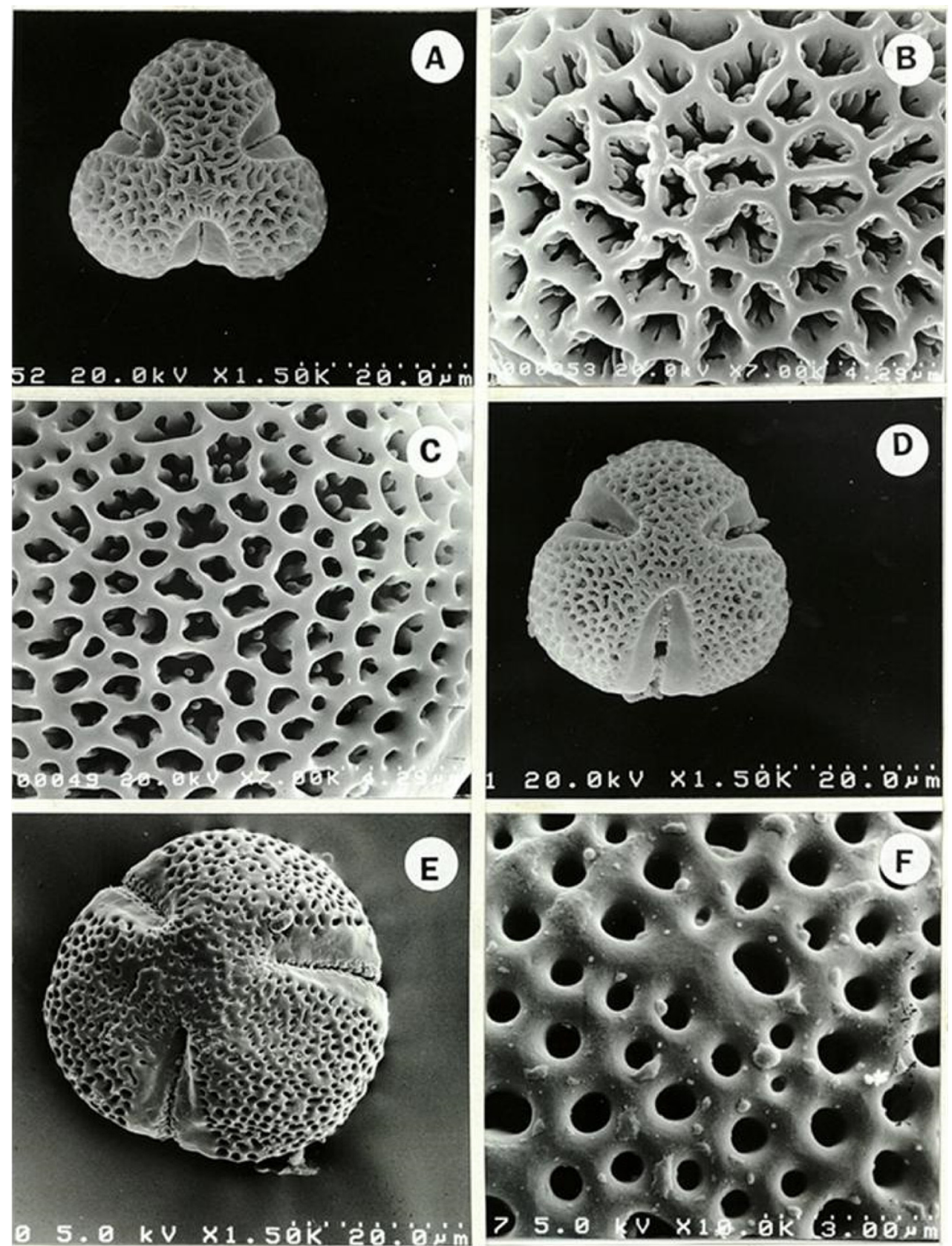

Fig. 2. Scanning electron microscopy micrographs of the subtribe Neoguillauminiinae species pollen. A, B. Calycopeplus oligandrus. C, D. C. paucifolius. E, F. Neoguillauminia cleopatra. B, C, F. Detail of the surface. 


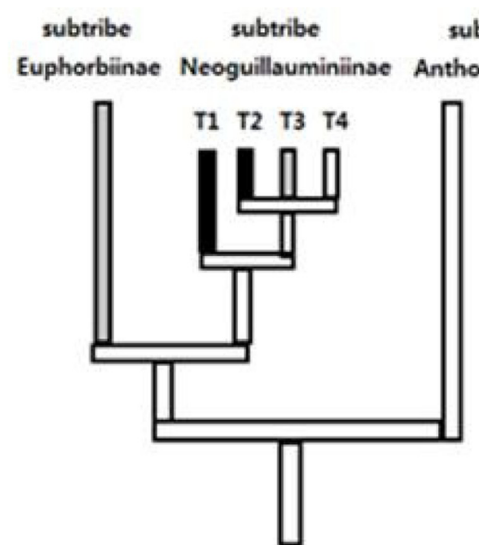

A subtribe

thosteminae

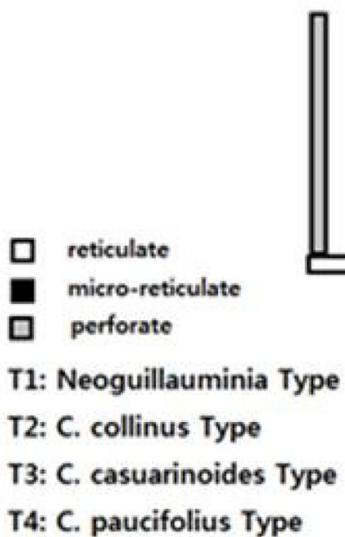

subtribe subtribe subtribe

Euphorbiinae Neoguillauminiinae Anthosteminae

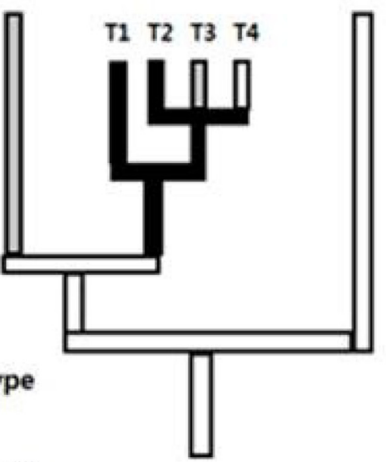

B

Fig. 3. Two conflicting, equally parsimonious reconstructions of the pollen character distribution on the simplified phylogenetic tree of the tribe Euphorbieae represented by Steinmann and Porter (2002). A. Two parallel occurrences of micro-reticulate state from reticulate pattern of pollen grain. B. One reticulate to micro-reticulate state change and a secondary loss of micro-reticulate state.

\section{Discussion}

\section{Pollen morphology and its systematic significance in the subtribe Neoguillauminiinae}

Webster (1975) first classified the tribe Euphorbieae, which consisted of about 2,000 species, into three subtribes, Anthosteminae, Neoguillauminiinae and Euphorbiinae. Recently phylogenetic studies using molecular data (Steinmann and Porter, 2002) have also supported the monophyly of Webster's three subtribes. However, analyses using morphological data only recovered Neoguillauminiinae and Euphorbiinae clades (Park and Backlund, 2002). Besides, the previous pollen studies (Park and Lee, 2013) and these results do not support such taxonomic treatments, indicating that pollen differentiation and molecular divergence do not concordant at the subtribe level in tribe Euphorbieae. However, the character of the well-developed sunken margo at the edge of colpi is an important evidence that species belonging to Neoguillauminiinae are included in the tribe Euphorbieae.

Within the subtribe Neoguillauminiinae sister-group relationship between Neoguillauminia and Calycopeplus (Park and Backlund, 2002; Steinmann and Porter, 2002) was proposed, and pollen characters such as size, amb and lumina shape support the significant divergence between above two genera. In particular, the traits of circular lumina and circular shape in polar view, which appear only in the pollen grains of $N$. cleopatra, support the recognition of Neoguillauminia as a monotypic genus by Croizat (1937).

Calycopeplus, the endemic genus of Australia, was described by Planchon (1861) on the basis of $C$. ephedroides $(=C$. paucifolius), Baillon (1866) and Bentham (1873) recognized this genus and added another species, C. marginatus. Recently, the first revision of Calycopeplus based on the morphological traits was performed by Forster (1995), and he described five species including two new species, $C$. collinus and $C$. oligandrus, in this genus.

Calycopeplus collinus, the endemic species of Northern Territory in Australia, is morphologically closely related to $C$. casuarinoides, but has been described as a new species with distinct differences in habit and length of involucre lobes. On the other hand, C. oligandrus is closely related to C. paucifolius but is distinguished from other species by very small involucres with few-flowered male clusters (Forster, 1995).

According to the pollen morphology of five species belonging to Calycopeplus, three pollen types were recognized. Among them, C. oligandrus and C. paucifolius belonging to C. paucifolius type had the same reticulate pattern, supporting the Forster's hypothesis that these two species have a close relationship. On the other hand, the morphologically similar Calycopeplus collinus and C. casuarinoides belong to different pollen types and this study could not support the hypothesis proposed by Forster (1995).

\section{Evolution of pollen characters within the subtribe Neoguillauminiinae}

Recent molecular phylogenetic analysis have shown that tribe Euphorbieae is divided into three subtribes, the earliest divergence of subtribe Anthosteminae, which is the sister-group relationship of the remaining two subtribes (Steinmann and Porter, 2002) (Fig. 3). 
Typical pollen grains of the species belonging to tribe Euphorbieae are 3-colporate with a thick colpus margin developed and exine characterized by the tactate-perforate patterns (Suárez-Cervera et al., 2001; Park and Lee, 2013). Among the tribe Euphorbieae, the subtribe Anthosteminae, the most basal clade within the tribe, consists of two genera, Anthostema and Dichostemma, and their pollen grains are reticulate (Park and Lee, 2013). Among the remaining two subtribes, pollen grains belonging to the subtribe Euphorbiinae are predominantly perforate, while species of the subtribe Neoguillauminiinae exhibit a variety of pollen grains of perforate, microreticulate and reticulate patterns (SuárezCervera et al., 2001; Park and Lee, 2013). Therefore, it is considered to be the most parsimonious hypothesis that the reticulate exine is regarded as the primitive character state of the tribe Euphorbieae, and the remaining microreticulate or perforate patterns are presumed to be derived from this.

Within the subtribe Neoguillauminiinae there are two equally parsimonious hypotheses about the evolution of exine characters. One is the case of two changes of microreticulate through parallel evolution from the primitive reticulate exine (T1 and $\mathrm{T} 2$ in Fig. 3A), and the other case is that the microreticulate pattern is differentiated from the reticulate state and then reversed to the reticulate pollen grains (Fig. 3B). In both cases, it is possible to evolve into the same stage of transformation. In all of the above two hypotheses, it can be assumed that the perforate pollen type (T3) was derived through a single evolution within the subtribe Neoguillauminiinae.

ORCID: Ki-Ryong PARK https://orcid.org/0000-0002-48997802 .

\section{Acknowledgments}

The author thanks two anonymous reviewers for their suggestions on earlier version of this paper.

\section{Conflict of Interest}

The author declares that there are no conflicts of interest.

\section{Literature Cited}

Baillon, H. E. 1866. Species Euphorbiacearum: Euphorbiacees Australiennes. Adansonia 6: 282-345.

Bentham, G. 1873. Calycopeplus. In Flora Australiensis 6. L. Reeve \& Co., London. Pp. 52-54.

Croizat, L. 1937. Notes on Euphorbiaceae, with a new genus and a new subtribe of the Euphorbieae. The Philippine Journal of Science 64: 397-412.

Erdtman, G. 1960. The acetolysis method: a revised description. Svensk BotaniskTidskrift 54: 561-564.

Forster, P. I. 1995. A taxonomic revision of Calycopeplus Planch. (Euphorbiaceae). Austrobaileya 4: 417-428.

Park, K.-R. and A. Backlund. 2002. Origin of the cyathium-bearing Euphorbieae (Euphorbiaceae): phylogenetic study based on morphological characters. Botanical Bulletin of Academia Sinica 43: 57-62.

Park, K.-R. and J.-H. Lee. 2013. Pollen morphology of subfamily Euphorbioideae (Euphorbiaceae). Korean Journal of Plant Taxonomy 43: 1-11.

Planchon, M. J.-E. 1861. La vraie nature de la fleur des Euphorbes expliquée par un nouveau genre d'Euphorbiacées. Bulletin de la Societe Botanique de France 8: 29-33.

Punt, W., P. P. Hoen, S. Blackmore, S. Nilsson and A. Le Thomas. 2007. Glossary of pollen and spore terminology. Review of Palaeobotany and Palynology 143: 1-81.

Steinmann V. W. and J. M. Porter. 2002. Phylogenetic relationships in Euphorbieae (Euphorbiaceae) based on ITS and $n d h \mathrm{~F}$ sequence data. Annals of the Missouri Botanical Garden 89: 453-490.

Suárez-Cervera, M., L. Gillespie, E. Arcalís, A. Le Thomas, D. Lobreau-Callen and J. A. Seoane-Camba. 2001. Taxonomic significance of sporoderm structure in pollen of Euphorbiaceae: tribes Plukenetieae and Euphorbieae. Grana 40: 78-104.

Thiers, B. 2018 [continuously updated]. Index Herbariorum: a global directory of public herbaria and associated staff. New York Botanical Garden's Virtual Herbarium. Retrieved May 2, 2019, available from http://sweetgum.nybg.org/science/ih/.

Webster, G. L. 1975. Conspectus of a new classification of the Euphorbiaceae. Taxon 24: 593-601.

Webster, G. L. 1994. Classification of the Euphorbiaceae. Annals of Missouri Botanical Garden 81: 3-32. 